Published as: Miller, H.J., F. Witlox \& C. Tribby (2013) "Developing context-sensitive livability indicators for transportation planning: a measurement framework". Journal of Transport Geography. Vol. 26, pp. 51-64.

\title{
Developing Context-sensitive Livability Indicators for Transportation Planning: A Measurement Framework
}

\section{Introduction}

The last two decades have witnessed a surge of interest in enhancing the livability of communities, and a growing commitment by governments to provide the framework, tools and data to plan and build livable communities. Although European governments have been proactive with respect to livability and sustainability plans (see, e.g., EU 2010), until recently, efforts in the United States have been mostly citizen-organized in response to local and regional issues (Deakin 2002; NRC 2002). This changed substantially in 2009 when the U.S. Environmental Protection Agency (EPA), the Department of Housing and Urban Development (HUD) and the Department of Transportation (DOT) formed a partnership to coordinate federal housing, transportation, and other infrastructure investments with the goal of creating more livable and sustainable communities. The Partnership for Sustainable Communities intends to identify policy and investment strategies that encourage safe, reliable and economical transportation choices, promote equitable and affordable housing, enhance economic competitiveness, support community revitalization and promote healthy, safe and walkable neighborhoods in rural, urban or suburban settings.

A key research need identified in the Partnership for Sustainable Communities is the development of livability measures and tools. The agreement calls for efforts to research, evaluate and recommend analytical measures that reflect the livability of communities, neighborhoods, and metropolitan areas. The intent is to use indices to benchmark existing conditions, measure progress and improve accountability in integrated planning efforts to enhance community livability. HUD, DOT, and EPA also intend to develop incentives to encourage communities to implement, use, and publicize the indices (USDOT 2009). 
Livability indices are not new: quality of life, and sustainability measures and rankings include scientifically-based policy measures such as the ecological footprint (Wackernagel and Rees 1996) and the human development index (UNDP 1990) and measures of inequality such as the Gini coefficient (Garner 1993; Yitzhaki 1979). However, new policy initiatives imply a greater emphasis on indicators to guide planning and investment decisions. These indices should be carefully constructed given these functional requirements. In particular, livability and sustainability indicators should be internally consistent or coherent with respect to measurement assumptions, transparent in the sense that they are easily understood and interpreted, and externally valid with respect to capturing all relevant aspects of the concepts.

This paper provides a measurement framework for developing and applying livability indices in transportation planning. With respect to internal consistency and transparency, we critically review the indicator construction process, focusing the discussion on issues relevant to transportation planning. With respect to external validity, we discuss multicriteria analysis (MCA): a set of techniques for eliciting preference structures in multiattribute decision-making (Jankowski 1995; Nijkamp et al. 1990). We also discuss techniques that allow indicators to capture the local context more fully. These include techniques that explicitly maintain stakeholder perspectives, and spatial analytic tools that can model spatial entities and relationships at varying levels of aggregation. We also discuss spatial decision support systems and the emerging concept of Geodesign as a framework for organizing these tools and technologies as well as integrating livability indicators into the broader planning process.

Although we discuss conceptualizations of livability, we do not intend to provide definitions of livability beyond identifying features that are relevant for the indicator construction process. We also do not intend to suggest what livability data should or should not be collected. In fact, it is often a good idea to collect data beyond the requirements for indicator construction: these can be used for "drilling-down" to derive additional detail or auxiliary information.

The next section of this paper provides background on defining livability, livability and transportation planning, indicators in policy and planning, and indicators for multidimensional concepts. After this background, the following section addresses 
issues associated with developing internally consistent and transparent indicators. Specifically, Section 3 provides a critical review of how to construct a composite index that summarizes a multidimensional concept such as livability, paying special attention to issues that are relevant to transportation. Section 4 discusses methods for developing externally valid indicators through capturing local context. These methods include the multiactor multicriteria analysis (MAMCA), spatial analytical tools, spatial decision support systems and the Geodesign process for organizing tools and technologies as well as incorporating livability indicators into the broader planning process. Section 5 concludes the paper with summary comments and directions for further research and application.

Although this paper focuses on livability measurement, we draw heavily from the literature on sustainability indicator construction since this latter problem is well-studied and has a mature body of theory and methodology with an admirable degree of rigor. Since sustainability and livability are closely related (arguably, the only difference is time scale; Litman 2010), lessons learned over four decades of sustainability measurement and accounting can provide valuable insights to the problem of livability indicator construction (as well as combined livability/sustainability indicators). Consequently, we use the term "livability" generically, although we use the term "sustainability" for references to that specific concept.

\section{Background}

Defining (urban) livability. A scan of the literature and the web suggests few precise and consistent definitions of urban livability. Many authors and commentators point to ideal city types as examples of livable communities. These ideal communities are typically moderately dense, diverse, walkable, safe, affordable, accessible and wellserved by public transit systems; in other words, the qualities usually associated with New Urbanist and smart growth principals (Banister 2008). For example, the Partnership for Sustainable Communities defines six principals of livability (USDOT 2009): 
- Provide more transportation choices. Develop safe, reliable and economical transportation choices to decrease household transportation costs, reduce our nation's dependence on foreign oil, improve air quality, reduce greenhouse gas emissions and promote public health.

- Promote equitable, affordable housing. Expand location- and energy-efficient housing choices for people of all ages, incomes, races and ethnicities to increase mobility and lower the combined cost of housing and transportation.

- Enhance economic competitiveness. Improve economic competitiveness through reliable and timely access to employment centers, educational opportunities, services and other basic needs by workers as well as expanded business access to markets.

- Support existing communities. Target federal funding toward existing communities - through such strategies as transit-oriented, mixed-use development and land recycling - to increase community revitalization, improve the efficiency of public works investments, and safeguard rural landscapes.

- Coordinate policies and leverage investment. Align federal policies and funding to remove barriers to collaboration, leverage funding and increase the accountability and effectiveness of all levels of government to plan for future growth, including making smart energy choices such as locally generated renewable energy.

- Value communities and neighborhoods. Enhance the unique characteristics of all communities by investing in healthy, safe and walkable neighborhoods - rural, urban or suburban.

These principals are not a conceptualization of livability: rather, they are objectives that underlie a deeper but unstated definition that spans economic, social and environmental dimensions. This reflects a widely accepted consensus about the dimensions of sustainability and livability that was first and most famously articulated by the wellknown Brundtland Report on sustainable development (Brundtland 1987; Litman 2007; NRC 2002). 
While livability and sustainability have general principles, the set of attributes that comprise a livable and/or sustainable community can vary from place to place and over time. Livability in particular has a strong local component due to the particular mix of attributes that emerge as people sort themselves among communities based on preference (and ability-to-pay), the importance of local trends in perceived quality of life, the local nature of politics, the varying availability of policy and planning prescriptions, and the need to ground these measures in local opinion for credibility (Myers 1987). Similarly, sustainability problems such as overconsumption and environmental degradation are not simply technical but have strong social and political components. Solutions to livability and sustainability problems occur within complex human and physical systems where local context can have dramatic effects on the outcomes (Prugh et al. 2000). The local component of livability does not mean that there are no general principles underlying livability indicators: rather, it suggests the relative importance of livability attributes can vary from place to place.

Livability and transportation planning. As a primary shaper of urban form and travel behavior, transportation systems have a key role to play in the development of livable and sustainable communities. Livability in transportation is about using the quality, location, and type of transportation facilities and services available to help achieve broader community goals such as access to good jobs, affordable housing, quality schools, and safe streets (USDOT 2010).

Although livability and sustainability have received heightened attention in recent years, livability in transportation is not new: community groups, developers and residents have long advocated for initiatives that promote accessibility, affordability, safety, smart growth and New Urbanism, with varying degrees of support from federal, state, and local agencies and planning organizations (USDOT 2010). In fact, Litman (2010) points out that livability and sustainability goals harmonize well with transportation planning objectives; Table 1 illustrates these overlapping goals and objectives. What has changed, more recently in the United States but earlier in Europe, is the mainstreaming of livability and sustainability concepts into the transportation planning (USDOT 2009, 2010). This 
is raising new requirements for data and measures that can help guide the planning process by charting progress towards livability and sustainability goals.

\section{Table 1: Transportation planning objectives that support sustainability and livability goals (Litman 2010)}

Indicators in policy and planning. The use of indicators to improve decision-making in policy analysis has a long tradition in applications such as economic development, quality-of-life assessment, environment and natural resource analysis and sustainability (Hezri and Dovers 2006). Indicators can have five main purposes (Dovers 2001; Failing and Gregory 2003; Hezri and Dovers 2006):

1. discriminating among competing hypotheses;

2. structuring the understanding of issues and conceptualizing solutions;

3. tracking performance towards goals and objectives;

4. discriminating among alternative policies either for specific decisions or general policy directions;

5. informing general users (public, stakeholders, community).

Although indicators have recently received new attention in transportation planning, Black (2010) points out that an indicator-based approach to transportation planning has been common for much of the past century. However, until recently, only one indicator was used, namely, operating speed or its inverse, congestion. Consequently, much of the effort involved in the traditional transportation analysis and planning process focused on predicting future points of congestion so they can be mitigated. Unfortunately, an emphasis on operating speed in transportation planning has encouraged excess travel, contributed to urban sprawl and undermined society's environmental, energy, and growth management goals. This has led to a shift from operating speed as the dominant transportation indicator to more comprehensive 
measures of personal mobility, accessibility, livability and sustainability across economic, social and environmental dimensions (Ewing 1993, 1996; Litman 2007).

Indicators for multidimensional concepts. There is a large literature on developing indicators for multidimensional concepts such as sustainability and livability (to a lesser degree) in policy and planning. Regardless of the specific methodology, all indicators share some common properties. These include the need to define the high-level dimensions of interest, identify the performance objectives within each dimension, construct individual indicators reflecting performance relative to the objectives, and measure variables for each indicator (Munda 2005; NRC 2002). Figure 1 illustrates these concepts and their linkages, including composite indicator construction (to be discussed below). Dashed arrows represent conceptual links, and solid arrows represent data flows.

\section{Figure 1: Conceptual foundation of multidimensional indicators}

For example, livability spans economic, socio-demographic and environment dimensions. Within each dimension, we need to define objectives such as maximize productivity (economic), minimize inequities (socio-demographic), and minimize environmental impact (environment). We then must define indicators relative to each objective, such as transportation cost (productivity), affordability (inequities) and air pollution (environment). Note that each objective may have more than one indicator. Finally, variables or indicator scores measure performance relative to an objective based on the stated indicator. For example, we might measure logistics cost relative to revenue, housing cost relative to income, or $\mathrm{CO}_{2}$ and PM-10 levels in an air shed (Munda 2005).

After defining a set of indicators for a multidimensional concept such as livability, the next question is how to handle the collection of indicators. Simple indicators maintain individual indicators as conceptually independent, while composite indicators combine individual indicators into a synoptic indicator (Zhou and Ang 2008).

Non-composite or simple indicators consist of a single indicator or a set of indicators. There are two types of simple indicators. Indicator sets are measurements 
across multiple dimensions and indicators that are maintained separately as an array. An example is the 58 indicators of sustainable development developed by the United Nations Commission on Sustainable Development (UNCSD 2001). An indicator set can be complex and difficult to interpret and therefore unable to provide a concise, synoptic summary of the performance being measured (Zhou and Ang 2008). A second type of non-composite indicator is an integrated indicator. These integrate multiple indicators by using a common unit across all indicators. A well-known integrated indicator is the ecological footprint proposed by Wackernagel and Rees (1996): this is the amount of land and water area a human population would hypothetically need to provide the resources consumed and the wastes produced. Another example is the genuine progress indicator (GPI): this indicator attempts to capture social and environmental factors not normally considered in gross domestic product accounting (Cobb et al. 1995). However, in practice it can be very difficult to find a common measurement unit across all dimensions and indicators of interest (Zhou and Ang 2008).

A composite indicator (CI) attempts to resolve the problem of finding a common measurement unit across dimensions and indicators. A composite indicator uses mathematical techniques to synthesize a single indicator from individual indicators measured in their native units (Munda 2005). CIs have become an increasingly popular way to assess the performance of cities, states, countries or other geographic units with respect to multidimensional phenomena such as livability, sustainability and development. They are often used to rank entities based on relative performance, as well as track their progress or regress over time (Massam 2002; Saisana and Tarantola 2002; Zhou and Ang 2008). A well-known example is the United Nations Human Development Index (Sagar and Najam 1998). Other examples include the Mercer quality of living index for world cities (www.mercer.com) and Florida's various creativity indices to assess a region's overall standing and prospects in an economy that values innovation (Florida 2002).

CIs have some disadvantages, including: i) sending misleading, non-robust policy messages if they are poorly constructed; ii) inviting simplistic policy conclusions; iii) subjective decisions in their construction; iv) disguising serious failings in some dimensions and make it more difficult to identify proper remedial action, and; v) they can 
lead to inappropriate policies if dimensions that are difficult to measure are ignored However, CIs have powerful advantages, including: i) summarizing complex or multidimensional issues to support decision-making; ii) providing a "big picture" that is easier to interpret than an array of separate indicators; iii) allowing the ranking of entities with respect to performance across a wide range of dimensions, and; iv) attracting public interest by providing a summary figure with which to compare the performance and progress over time (Saisana et al. 2005; Zhou and Ang 2008). These advantages can be maximized, and the disadvantages minimized, through proper CI construction.

The next section of this paper focuses on the construction of internally-consistent and transparent CIs. However, we do not advocate CIs as the singular solution to livability measurement in transportation planning. Single indicators and/or indicator sets are useful alternatives, and can also serve as supplements to a synoptic index such as a CI. For example, indicator sets can be useful when drilling-down into the database to help understand observed variations in overall livability suggested by a CI. Also, with the exception of the aggregation step, the principles of proper CI construction can also inform the construction of individual indicators or indicator sets. For example, it may be a good idea to normalize individual indicators or indicator arrays even if they are not aggregated into a CI. For example, normalization could be useful for indicator visualization in a summary, dashboard format.

\section{Constructing Consistent and Transparent Composite Indicators}

There are two main strategies for constructing CIs (Zhou and Ang 2008). The indirect approach involves normalizing the individual indicators, assigning weights reflecting their relative importance, and then combining the weighted normalized variables to derive a synthetic composite indicator. This process often involves methods from multicriteria analysis (MCA). MCA is a set of techniques for identifying choice alternatives satisfying the objectives of the parties involved in a multi-attribute decisionmaking process, and reducing the set of feasible alternatives to identify the most preferred alternatives (Jankowski 1995; Nijkamp et al. 1990). In the case of CI construction, MCA provides techniques for identifying indicators, eliciting weights 
reflecting the relative importance of the indicators, aggregating the indicators to develop the CI, and conduct sensitivity analysis (Munda 2005; Zhou and Ang 2008).

The direct approach to constructing CIs involves obtaining the composite indicator endogenously and unequivocally within a formal framework. The most common direct method for constructing CIs is data envelopment analysis (DEA). DEA is a non-parametric, linear programming-based technique used in operations research and economics to analyze the relative efficiency of firms based on their combined inputs and output and identify combinations of resource inputs that maximize efficiency. As part of this process, DEA calculates the shadow prices or hidden (unknown) costs associated with the given combination of resources. When applied to CI construction, the shadow prices are the desired indicator weights given an appropriate definition of efficiency (Cherchye et al. 2008).

In this section of this paper, we will focus the discussion on the indirect method of constructing CIs for transportation. While direct methods such as DEA certainly have value, indirect methods offer a strong advantage: the capability for wider input into the livability measurement process. Given the contentious nature of many transportation projects, as well as the wide variety of stakeholders involved, a transparent and open process is essential if livability measurement is to be adopted in transportation policy and planning. In contrast, direct methods are vulnerable to rejection as technocratic and possibly elitist in public decision-making (although there have been some attempts to integrate the two approaches; see Ramanathan 2006; Zhou and Fan 2007). In addition to political acceptability, there are also ethical issues involved in the construction of a CI. The relative weights associated with indicators in a CI necessarily involve value judgments; therefore consistency and transparency relative to the assumptions used in constructing a CI should be a priority (Munda 2005).

The major steps involved in constructing composite livability indicators using indirect methods based on multicriteria analysis (MCA) techniques include: i) identifying objectives, indicators and weights; ii) normalization; iii) aggregation of the weighted indicators, and; iv) sensitivity analysis. This is not necessarily a linear process: there may be feedback to earlier steps, particularly after sensitivity analysis (Munda 2005; Zhou and Ang 2008). 


\subsection{Identifying objectives, indicators and weights}

A critical step in measuring livability is defining the objectives, the indicators that measure performance with respect to the objectives and the relative importance of the indicators in the composite livability indicator. These tasks are interrelated, and consequently can be conducted in an iterative manner. There are software environments for facilitating these tasks known as decision support systems (DSS). DSS allow decision makers to explore the consequences of their choices through software tools, graphics and visualizations, and can also provide services for supporting interaction and collaboration in group decision making (Jankowski et al. 1997; Witlox 2005). We will return to the topic of DSS in Section 5.

Objectives and indicators. Identifying objectives and indicators is often conducted in an informal manner or semi-structured manner, such as interviews and "brain-storming" with focus groups and stakeholders. Another possible approach is to examine policy statements and secondary information sources from relevant stakeholder groups and analyze these to derive indicators to reflect their concerns. A third possibility is to conduct role-playing exercises where members of the decision team role play the position of key stakeholder groups to ensure their perspectives are included when deriving indicators (Dodgson et al. 2009).

Regardless of how they are derived, unambiguous indicators should have the following properties (Keeney 1980; Malczewski 2000; also see Litman 2007):

1. Comprehensible: An indicator is comprehensible if its level clearly indicates the degree of achievement for its associated objective.

2. Measurable: An indicator is measurable if it is practical to assign a number to it performance and it is possible to assess preferences for different levels of the indicator value.

3. Completeness: The indicators should cover all relevant aspects of the phenomenon being assessed, and adequately indicate the degree to which the overall objective is achieved. 
4. Operational: It should be practical to measure in the indicator in practice, e.g., the required data should not be unduly expensive to collect.

5. Decomposable: Performance relative to one indicator can be evaluated independently of performance with respect to other indicators.

6. Nonredundant: Indicators should be nonredundant to avoid problems of multiple counting.

7. Minimal: The set of indicators should be as small as possible.

Properties 6 and 7 should not suggest collecting only the minimal amount of data possible as a general policy. Rather, these properties dictate that the indicators that comprise an indicator set, an integrated indicator or aggregated into a CI should be nonredundant for parsimony and ease of understanding. Drilling-down for exploration and explanation will involve additional, perhaps redundant, data.

Indicator weights. Closely associated with the problem of deriving an appropriate set of indicators is the relative importance or weights associated with each indicator. The weights should be scale-free, satisfying the properties $0 \leq w_{j} \leq 1$ and $\sum_{j=1}^{n} w_{j}=1$ where $n$ is the number of indicators. Combined with variable normalization (see below) this allows the construction of a scale-free CI that varies between zero and one, enhancing clarity and interpretation.

Another possibility is to choose weights that represent the monetary value of each indicator, with the result that the CI score for each entity is expressed as the overall monetary value associated with livability in that entity. Although this approach has merit - for example, real-world metrics such as dollars or euros can be meaningful to decision makers and the public at large - it has two substantial problems. First, it is misleading to express some livability and sustainability indicators (in particular, those within the social and environmental dimensions) in monetary units. This assumes that the particular indicator can be traded for money; in some cases, this is nonsensical (a topic we will return to below). Second, although there may be good reasons to compress multiple indicators into an overall score, expressing this score in monetary units brings the danger of reifying a synthetic construction. A real number score between zero and one that can 
be interpreted as a ratio value allows valuable quantitative comparisons, but leaves these comparisons within an abstract metric. This provides a persistent reminder not to reify the $\mathrm{CI}$ as anything other than a (carefully) constructed summary measure.

There is a wide range of methods for eliciting attribute weights or rankings among attributes (see Figueria et al. 2005; Greene et al. 2011). A common method is analytical hierarchy process (AHP) (Saaty 1980, 1990). AHP decomposes a multi-attribute problem into a hierarchy of the overall goal, criteria, subcriteria and alternatives. Decision makers and stakeholders involved in the process are to conduct pairwise comparisons between subcriteria. Analysis of the resulting judgment matrix allows the derivation of the relative weights for each indicator, as well as a consistency index to assess the degree of consistency in the pairwise judgments (Duke and Aull-Hyde 2002). A possibility with AHP is rank reversal: this occurs when rankings among existing indicators change after the insertion of a new indicator. This can be interpreted as a problem with the methodology, or a reflection of real world behavior. Given the former interpretation, there are methods for avoiding this problem (e.g., see Schenkerman 1994; Wang and Elhag 2006).

A problem in developing livability indicators is the ambiguity about the conceptual structure of objectives and dimensions. For example, it is possible that an objective may reflect more than one dimension, or an indicator may reflect more than one objective. For example, minimizing inequities could be interpreted as having both economic and social dimensions. Similarly, affordability could reflect the objectives of minimizing inequities and maximizing economic efficiency. A third example is that minimizing natural resources has both environmental as well as economic efficiency aspects. Fuzzy structure modeling (FSM) allows modeling of ambiguous relationships in the calculation of indicator weights (Sakamoto and Fukui 2004).

Techniques for deriving preference weights in MCA are typically applied in group settings, comprising decision-makers, stakeholders and other parties interested in the definition or decision problem. The objective is to derive a single set of preference weights that reflect a consensus of the individual perspectives. However, given the wide range of stakeholders concerned with transportation, and the contentious nature of many transportation policies and projects, it is not guaranteed that these weights will be robust 
and uncontested, particular if there are differences in informal power and influence among stakeholders. The synthetic consensus preferences can mask crucial preferential differences among the stakeholders (de Chazal 2010; Macharis et al. 2009; Strager and Rosenberger 2006). The preference structure underlying complex concepts such as livability can also be contingent on contextual factors, and can consequently change over time (Allen 2010). For example, Shafer et al. (2000) found different perspectives on the impact of urban greenways on perceived quality-of-life based on the individual's use of the facility (recreation versus commuting). Strager and Rosenberger (2006) found differences between the preferences of "outside experts" (who tended to focus on the general principles underlying the issue) and the preferences of "local stakeholders" (who tended to focus on context-specific knowledge about the issue in the local setting) with respect to a land conservation proposal.

Rather than confounding the process, recognizing differences in influence and preference can be helpful in complex decision processes such as livability definition and measurement. The true consensus may be different from the aggregation of individual preferences if there is room for debate and change in the process. For example, in the outside expert versus local stakeholder dynamic discussed above, Strager and Rosenberger (2006) found that the otherwise confounding phenomenon of rank reversal resulted from unmeasured criteria important to local stakeholders. Conversely, the

process of obtaining consensus can raise awareness of some stakeholders to universal, broader issues. They conclude that although the objective of MCA is to simplify complex decisions, it is useful to also treat the process as a form of discursive democracy where preferences are explored and refined.

\subsection{Normalization}

Since individual indicators are often (if not always) measured in different metrics, normalization is essential. The objective is to develop metric free measures where higher positive values reflect greater desirability (i.e., better performance relative to the stated objective). Several normalization techniques are available, including Z-score 
transformations, linear normalization, and distance from the best and worst performer (Munda 2005; Zhou and Ang 2008).

Although seemingly mundane, the normalization process can involve judgments and decisions that strongly impact the indicator. Normalization often involves choosing a reference point and a measure of difference from this reference. This reflects a judgment about ideal performance (or lack of performance). For example, decisions must be made regarding the best and worst performers in measuring distances to these extremes. One possibility is to follow a relative perspective and choose the empirical best and worst performers with respect to the current state of the system. However, if the performance is bad across the entire system (e.g., all cities are unlivable), the results are measures of relative differences in bad performance without a sense of progress with respect to a desired performance goal. Alternatively, we can follow an absolute perspective and choose the best and worst possible performances with respect to a stated ideal. However, these ideals may be difficult to ascertain or may be unrealistic, rendering the normalized measure meaningless.

\subsection{Aggregation}

The most common way to combine the indicators is through simple additive weighting (SAW):

$$
I_{i}=\sum_{j=1}^{n} w_{j} x_{i j} i=1, \ldots m
$$

where $x_{i j}$ is the normalized indicator $j$ for entity $i$, and $w_{j}$ is the normalized weight associated with indicator $j, n$ is the number of indicators and $m$ is the number of entities (e.g., geographic units such as cities or neighborhoods). SAW has some advantages, including simplicity and ease of understanding. However, SAW makes several strong assumptions regarding the indicators and dimension being measured by the index (Munda 2005; Zhou and Ang 2008). Indicator weights in the SAW technique can be also be interpreted as trade-off ratios between the variables (Munda and Nardo 2005). This implies that preferences among the indicators and variables are compensatory: that is, bad performance in one dimension can be compensated by good performance in another. This is questionable in many circumstances, and perhaps no more than in livability and 
sustainability performance measurement. For example, how much $\mathrm{CO}_{2}$ in an urban air shed should be substituted for greater housing affordability? The linear combination in the SAW approach also assumes preference independence (Munda 2005). In reality, complex multifaceted decisions often have inter-attribute relationships such as conditional relevance (dependencies among attributes change in relevance due to the presence or absence of other attributes) and conceptual interaction (the relative importance of attributes changes depending on the values of other attributes; see Witlox et al. 2009).

At the other extreme, we could alternatively assume that indicators across social, economic and environmental dimensions are strictly non-compensatory: they cannot be substituted in any precise manner. A weighted product (WP) aggregation assumes noncompensatory relationships among indicators since poor performance in one indicator cannot be compensated by good performance in another (Ebert and Welsch 2004; Zhou and Ang 2008):

$$
I_{i}=\prod_{j=1}^{n}\left(x_{i j}\right)^{w_{j}} i=1, \ldots, m
$$

Compensatory versus non-compensatory aggregation of indicators parallels a conceptual debate in the sustainability literature between weak sustainability versus strong sustainability. Compensatory aggregation is consistent with weak sustainability: this assumes unlimited substitutability between natural resources and human-made capital, with the implication that sustainability is obtained if the total net capital (both natural and human-made) remains positive. Non-compensatory aggregation is consistent with strong sustainability: this perspective views substitutability with suspicion due to the irreplaceability of natural resources and the aversion of some individuals to natural resource loss regardless of compensation by human-made capital (Gútes 1996; Neumeyer 2003). There have been attempts to reconcile or modify these extreme positions to make them more practical for empirical evaluation, with varying degrees of success (see, e.g., Ekins et al. 2003; Hediger 1999; also see Neumeyer (2003) for analysis and discussion).

Continued progress in the MCA literature have led to the creation of aggregation methods that allow greater flexibility and the possibility of intermediate solutions 
between the extreme positions of strict substitutability or strict non-substitutability across all indicators. Weighted displaced ideal (WDI) and ordered weighted averaging (OWA) methods try to find compromises between compensatory and non-compensatory methods. WDI is based on the idea that the best system should have the least distance from the ideal system. WDI sums a distance function of the weighted indicators:

$$
I_{i}=\left[\sum_{j=1}^{n} w_{j}^{p} x_{i j}^{p}\right]^{1 / p}
$$

where $1 \leq p \leq \infty$ defines the distance metric. Specifying the distance metric determines the trade-off relationships among the indicators. If $p=1 \mathrm{WDI}$ is equivalent to SAW. If $p \geq 2$, WDI is a non-linear aggregation of the individual indicators. As $p \rightarrow \infty$, $I_{i}=\min \left[w_{j} x_{i j}\right]$ meaning that the entities are compared by their poorest performance across all indicators. The distance metric could be included as a parameter in the decision process: e.g., one could plot CI behavior as a function of $p$ as well as drill-down and explore solutions for some parameter settings to support group consensus on the appropriate trade-off relationships to embody in the CI (Diaz-Balteiro and Romero 2004; Zeleny 1982; Zhou and Ang 2008; Zhou et al. 2006).

OWA is a set of aggregation operators that also allow a high degree of flexibility (Yager 1988). OWA involves SAW-like aggregation, but with weighted indicators ordered by value and additional weights reflecting their position in this sequence:

$$
I_{i}=\sum_{j=1}^{n} v_{j} z_{i j} i=1, \ldots m
$$

where $\quad z_{i 1} \geq z_{i 2} \geq \cdots \geq z_{i n}$ is the sequence of $n$ weighted indicators $\left(w_{1} x_{i 1}, w_{2} x_{i 2}, \ldots, w_{n} x_{i n}\right)$ arranged in descending order, and $\left\{v_{j}\right\}$ are a set of order weights. Similar to the indicator weights, order weights are also scale-free measures such that $0 \leq v_{j} \leq 1$ and $\sum_{j} v_{j}=1$. However, order weights reflect the importance of the indicator's position when ranking them from best to worse performance for each entity. Different order weights reflect different logical operators applied to the weighted indicators. For example, if we choose the weights $v_{\min }=(0,0, \ldots, 1)$ then $I_{i}=\min _{j}\left[w_{j} x_{i j}\right]$ or the minimum value of the weighted indicator set, meaning that 
entities are evaluated by the worse-performing and/or least important indicator. This is equivalent to the logical AND operator applied to the weighted indicators since entities must perform well on all indicators to perform well as a unit. Conversely, the weights $v_{\max }=(1,0, \ldots, 0)$ correspond to $I_{i}=\max _{j}\left[w_{j} x_{i j},\right]$ or the maximum value of the set, meaning that entities are compared based on their best and/or most important indicator. This is equivalent to the logical OR operator since only one indicator must perform well for entities to perform well. Varying the order weights between the $v_{\min }$ and $v_{\max }$ captures the entire range of possible MIN (OR) and MAX (AND) combinations between those extremes, including the SAW method (Malczewski et al. 2003; Rinner and Malczewski 2002).

There are several methods for determining order weights, some based on fuzzy sets since this is the origin of the OWA method; see Jiang and Eastman (2000), Xu (2005), Yager (1988) and Yager (1997). Malczewski et al. (2003) developed a method based on a parameterization of MAXness (ORness). This parameter can be used to determine in optimal sets of weights based on a maximum entropy criterion. In addition, a function based on the MAXness parameter provides a systematic method for modifying the order weights and generate different solutions. Malczewski (2006) developed a fuzzy set approach that translates proportional linguistic quantifiers (e.g., the following classes: few, half, most, all) into a set of order weights.

As noted previously, contentious dynamics can occur between professionals who emphasize generalities and citizens who emphasize context, as well as between outsiders who emphasize what is good overall and locals who emphasize neighborhood effects (Strager and Rosenberger 2006). Bell et al. (2007) illustrate how to capture these types of dynamics using the OWA technique. Standard indicator weights provided by professional experts reflect global considerations while the OWA order weights allow local, casespecific, data-driven factors to have varying degrees of influence. They generate a range of scenarios with different levels of global versus local trade-offs by systematically varying the order weights.

\subsection{Uncertainty and sensitivity analysis}


The final step in constructing CI is conducting sensitivity and uncertainty analyses. Sources of uncertainty and sensitivity in CIs include: i) selection of indicators; ii) data selection and cleaning; iii) normalization; iv) weighting method; v) weights, and; vi) aggregation method. Uncertainty analysis focuses on how errors in the input measures propagate and affect the CI values, while sensitivity analysis assesses how much each individual source of uncertainty contributes to the output variance. The result of these analyses is a CI that is a distribution rather than a single point estimate. While this may appear to weaken the utility and especially the comparability of the CI, it can make the assessment more transparent and ultimately more robust (Saisana et al. 2005). Error propagation methods are available for the weighting methods, weights and normalization and information loss measures are available for the aggregation method (see Triantaphyllou and Sanchez 1997; Zhou et al. 2006). Saisana et al. (2005) developed an iterative methodology for CIs that combines uncertainty analysis and sensitivity analysis for assessing the effect of normalization, weighting method and weights. However, uncertainty and sensitivity analysis is a relatively underdeveloped topic in the CI construction literature; in particular, there are no methods that can address spatial error propagation or sensitivity due to spatial aggregation and partitioning of the underlying units when applying these indicators to geographic entities such as neighborhoods, cities or regions.

\section{External Validity: Adapting Indicators to Local Context}

The techniques discussed previously in this paper are methods for constructing livability indicators that are coherent, transparent and externally valid. Following the principles of good indicator construction leads to indicators that are internally consistent and transparent. MCA techniques allow for external input regarding indicators and relative importance weights. While this is sufficient for many indicator applications such as ranking countries or cities based on livability or sustainability, application in transportation policy and planning requires some enhancements to these techniques, particularly if these indicators are used in policy and plan evaluation.

One set of enhancements relate to the diverse stakeholders typically involved in the planning process. Transportation stakeholders can include metropolitan planning 
organizations, local, governmental units at all levels, transportation and transit agencies, businesses, community organizations and local citizens. These stakeholders can have widely diverse perspectives about livability and (in particular) what components of livability are important. Given the contentious nature of many transportation projects, attempting to reach a consensus on livability such as required in a standard MCA process may not only be difficult, but can also have the effect of reifying otherwise contingent definitions as somehow true and universal, with negative consequences for their political acceptability (Macharis et al. 2009).

Geographic context is also important to transportation planning. Transportation has strong geographic footprints, both explicitly with respect to the location of infrastructure and services, as well as implicitly with respect to impacts on human and physical systems such as land-use and the environment. Transportation system performance also varies by space and time: congestion is the most evident example. Finally, the distribution of people with respect to the transportation system is often sorted spatially and temporally according to socio-economic, demographic and cultural factors, meaning that transportation has varying impacts on social groups based on location. Assessing the impacts of transportation on livability therefore requires sensitivity to geographic context.

This section discusses techniques for capturing local context in indicator construction and application. The first is a set of techniques for explicitly incorporating and maintaining individual stakeholder perspectives in the MCA process. The second are spatial analytical techniques that provide methods for capturing the geographic context of

transportation systems and spatial relationships among livability indicators. The third set of techniques is spatial decision support systems (SDSS) that utilize digital maps, geovisualization and spatial analysis techniques to support complex, multi-attribute problem-solving for mappable phenomena such as transportation. Related to SDSS is the emerging concept of Geodesign that can provide an organizing framework for these tools and technologies as well as a framework for integrating livability indicators into the broader planning process.

\subsection{Incorporating stakeholder perspectives}


As noted previously in this paper, it is possible to explore different weighting scenarios in MCA; for example, the trade-offs between global principles and local context using the order weights in the OWA aggregation technique (see Bell et al. 2007). A more comprehensive approach is to build and maintain multiple stakeholder perspectives explicitly throughout the CI construction, evaluation and application process. This can lead to better understanding of different stakeholders' perspectives and the trade-off required for a consensus. This can allow stakeholders to reflect on their objectives and consider more carefully their rationale for their conceptions and objectives. Also, the fact that stakeholders know that their preferences will be maintained and included in a comprehensive evaluation can motivate them to make more appropriate and reasonable assessments (de Chazal 2010; de Chazal et al. 2008; Macharis et al. 2009).

The multi-actor multicriteria analysis (MAMCA) extends the MCA to explicitly incorporate and maintain diverse stakeholder viewpoints throughout the process instead of only during the initial stages of problem analysis, identification of objectives and indicators and derivation of weights (Macharis et al. 2009; Macharis et al. 2010). Figure 2 illustrates the MAMCA process. It begins with the definition of dimensions and objectives as in the standard MCA process. However, it introduces a second step, namely, stakeholder analysis. This stage identifies stakeholders in the transportation project and conducts an in-depth analysis of their objectives and their relative importance. These are maintained in the next stage when indicators and weights are derived. However, in a MAMCA, the weights are defined as the importance the stakeholder attaches to her goals. Each stakeholder can be assigned a weight reflecting their importance in the indicators construction process. This could be equal for all stakeholders, although it some cases it is defensible to give a stakeholder greater weight (e.g., a governmental or regulatory agency).

\section{Figure 2: The multi-actor multicriteria analysis (MAMCA) process (Macharis 2007)}

As an example, Witlox et al. (2010) apply the MAMCA method to a contentious logistics facility in Ghent, Belgium. Figure 3 illustrates the stakeholders and stakeholder weights associated based on interviews with 19 local organizations. The four stakeholders 
groups - receivers (customers), the transport sector, facility employees and society (city inhabitants, commuters, tourists, shoppers, governments) -were given equal weights. Figure 3 also illustrates the critical attributes and the preference weights derived for each stakeholder.

\section{Figure 3: Example MAMCA weights (Witlox et al. 2010)}

The facility considered five alternative operating policies: 1) day deliveries; 2) night deliveries; 3) evening off-peak deliveries; 4) morning off-peak deliveries, and; 5) night deliveries with mitigation efforts. Figure 4 illustrates the overall result: there is a clear preference for day deliveries mostly due to strong attitudes of the employees, while all off-peak alternatives score similarly. This raises the question of exploring alternative solutions. Figure 5 drills down and focuses on the preferences for two stakeholders, the transport sector and society. The plot illustrates the weighted attributes for each stakeholder and each policy's relative performance across these attributes and overall. Both stakeholders share an aversion to daytime deliveries but disagree with respect to preference for morning versus evening off-peak deliveries.

The stakeholder-based analysis in MAMCA facilitates the search for potential conflicts as well as aspects of agreement, as well as the reasons behind these agreements or disagreements, facilitating a discursive democratic approach to livability measurement in transportation planning. MAMCA techniques and visualizations could be used to support stakeholder weighting scenario analysis; e.g. changing stakeholder weights to reflect shifting emphasis between professionals and citizens or outsiders versus locals (Bell et al. 2007; Strager and Rosenberger 2006). As with standard sensitivity analysis in CI construction, a useful result could be the range of livability scores across different weighting in addition to a single compromise score.

It is crucial to note we are not advocating "crowd rule" for livability measurement in transportation planning. As mentioned above, greater weights could be given to experts and government entities, especially regulatory authorities. We could also define an abstract stakeholder reflecting current scientific consensus on the concept and give this 
stakeholder an appropriate weight. In many situations it may be useful to think of MAMCA as adjusting rather than redefining global livability definitions, using local input to customize general principles derived from science and regulatory authority to better fit local context.

Figure 4: MAMCA overall results across all stakeholders (Witlox et al. 2010)

Figure 5: MAMCA stakeholder preferences: Transport sector (top) and society (bottom) (after Witlox et al. 2010).

\subsection{Incorporating geographic context}

GIS allows high-resolution and accurate representations of spatial objects and their interrelationships. Spatial objects such as transportation infrastructure, buildings, neighborhoods, cities, etc., can be represented in their natural form as points, lines, polygons or fields rather than through approximations such as centroids representing zones. GIS allows higher resolution and more accurate spatial relationships among entities such as distance, connectivity, shortest path and direction. This greatly expands the flexibility and power of analytical measures and methods built on these data (Miller and Wentz 2003).

Highly aggregate indicators often fail to capture nuanced spatial effects since they mask heterogeneity in the underlying disaggregate distribution. Also, a large number of disaggregate spatial distributions can be consistent with the same aggregate state, meaning it is impossible in principle to untangle competing explanations and policy interventions (O'Kelly 2010). For example, commuting efficiency measures compare commuting distances to determine the degree of spatial match between residences and work locations. These measures are highly influenced by the spatial representation of the system; e.g., aggregate traffic analysis zones with Euclidean distances versus disaggregate neighborhoods with network-based distances (Horner 2004; Niedzielski 
2006). Spatial disaggregation also supports disaggregation by trip purpose, socioeconomic status, gender, age and other factors to capture social and cultural differences in this livability indicator (Horner and O'Kelly 2007; Horner 2002). Similarly, transportation performance measures such as travel time, congestion, level of service give different depictions when measured at the zone level, the corridor level or at level of the individual links (Zietsman and Rilett 2008). In addition to spatial disaggregation, temporal disaggregation is also becoming more feasible as frequently updated data and real-time data streams become increasingly available. This can allow greater sensitivity to the multi-level and complex dynamics that typify land-use, transportation and human activity systems (Geurs and van Wee 2004; Van Acker et al. 2007).

Despite capabilities for high-resolution geospatial measurement, it is often necessary to use aggregate spatial units for data collection and reporting purposes. Some of these units, such as census units, traffic analysis zones, postal codes, and so on, are constructed by fiat and have a degree of arbitrariness with respect to the distribution of the property in the real world. This can drastically affect the results of livability mapping and analysis (see NRC 2002, Figures 3.2-3.6). The problem of arbitrary geographic units and their effects on measurement, mapping and analysis is known by the awkward label modifiable areal unit problem or MAUP (see Openshaw and Taylor 1979; Wong 2009). The problem is simple to state, but difficult to solve: if the units are defined using an arbitrary spatial scale and/or with arbitrary boundaries, than the results of the measurement and analysis are arbitrary: they can be changed by manipulating the scale or boundaries (Wong 2009). This issue has received little attention in the literature on constructing social indices (Schuurman et al. 2007).

Unfortunately, there is no simple solution to the problem of arbitrary spatial units (Wong 2009). One possibility is to develop statistically optimal spatial units for reporting data, but this can vary by indicator type, and may not be practical or politically realistic (e.g., Openshaw 1978; Openshaw and Rao 1995). Methods for addressing scale-related issues include assessing impacts of scale effects, development of scale-free fractal methods for spatial analysis, and the use of advanced geostatistical methods to model the scale effects. Spatial interpolation methods can be used to address problems with arbitrary boundaries by interpolating the data to more appropriate units (e.g., Flowerdew 
and Green 1992; Gotway and Young 2002). A straightforward method facilitated by GIS software is to conduct sensitivity analysis using different scales and zoning systems; this could be part of the indicator construction process similar to sensitivity and uncertainty analysis based on weights, normalization and weighting methods. Schuurman et al. (2007) conduct a sensitivity analysis of area-based deprivation indices and conclude that artifacts are best ameliorated by using large map scales (i.e., the smallest unit of analysis possible), a conclusion consistent with much of the broader literature on the MAUP.

In addition to appropriate representation of spatial entities, spatial analytical techniques can capture spatial dependency relationships among attributes and indicators. Spatial dependency refers to the tendency for things that are spatially proximal to be more related. Observed positive or negative relationships between proximal locations can occur due to a casual relationship that is mitigated by space (e.g., active transportation spreading from a neighborhood to surrounding neighborhoods due to social contagion), because some unmeasured, underlying factor affects both locations because they are proximal (e.g., young, fit people tend to live in specific neighborhoods), or both. Understanding spatial dependencies among indicators is useful for both scientific understanding as well as policy since spatial associations can tell us both what and where to intervene (also when given the appropriate spatio-temporal data and methods).

Transportation is particularly subject to spatial dependency effects due to externalities: positive or negative effects that are not captured by the direct cost or benefit to the user. Air pollution, noise, accidents and sprawl are examples of negative externalities from transportation that accrue to others besides the system users. Transportation externalities can be multi-faceted and multi-scale. Passive use benefits are positive externalities that consist of three components: option values, indirect benefits, and existence benefits (Geurs and van Wee 2004). Option values are the benefits of having the option to use the transit investment, say, if the primary automobile mode is unavailable. Indirect benefits are effects accrued by others consuming services, such as transit consumption by passengers reducing congestion for automobile users. Existence benefits are effects related to potential future use or other people's use. Positive and negative externalities often have a spatial expression, attenuating with distance from the 
process generating the externality with the scale of the effect depending on the externality type (Lakshmanan et al. 2001; Papageorgiou 1978).

Spatial analysis techniques can be used to assess spatial dependency among livability indicators and assess the effects of transportation externalities, providing greater insight into livability and also suggesting policy interventions (e.g., what is the total, system-wide effect on livability from lowering traffic flows through a specific corridor?) (Black et al. 2002). Spatial dependency can be measured using both aggregate and disaggregate spatial autocorrelation statistics, the former providing a single summary assessment statistics and the latter capturing spatial heterogeneity in the dependency and allowing identification of "hot spots" with high degrees of high or low spatial association (see Anselin 1995; Fotheringham 2009). Spatial regression methods explicitly capture spatial dependency in their structural terms, error terms or both, allowing estimation of spatial associations in multivariate relationships (Fotheringham et al. 2000, 2002; LeSage and Pace 2009). Recent progress in modeling spatial externalities include hedonic price modeling for the indirect benefits on housing prices of pedestrian and transit design (Bartholomew and Ewing 2011), air quality (Kim et al. 2010), environmental quality (Carruthers and Clark 2010) and greenspaces (Conway et al. 2010). Other applications of spatial hedonic price models include willingness-to-pay studies for the benefits of river flows (Hanley et al. 2003), and use and non-use benefits of forest management policies (Horne et al. 2005)

\subsection{Spatial decision support and Geodesign}

Decision support systems (DSS) are digital environments that support MCA in single and multi-person decision situations (Turban 1993). DSS are often visually-oriented, supporting MCA techniques through intuitive user interfaces and graphics. Spatial decision support systems (SDSS) are digital environments that use GIS functionalities such as spatial database management, cartography and spatial analysis to support complex geographic decision problem-solving such as locating a new facility or configuring a transportation network.

SDSS combine MCA techniques with the power of digital cartography. Solutions are typically visualized both as attribute plots as well as in map format, aiding 
understanding and helping to ground results in a familiar geographic context. In addition to the powerful technological benefits of GIS, there are deeper conceptual linkages between MCA and a traditional geographic technique known as suitability mapping. There is a natural correspondence between attributes in MCA and map layers in suitability mapping, and cartographic modeling and overlay techniques can implement aggregation functions such as SAW and OWA efficiently and effectively (Greene et al. 2011; Jankowski 1995; Malczewski 2004; Nyerges and Jankowski 2010).

In addition to supporting all aspects of the indicator construction process, SDSS are effective at collaborative spatial decision-making, primarily because the map provides an effective medium and language for group discussion and deliberation (Jankowski et al. 1997). Collaborative SDSS can support group decision-making in a variety of modes, including at the same location/time (digitally-enhanced meetings), same location at different times (collaborative work environments and collaboratories), different locations at the same time (teleconferences, virtual meetings) and different locations at different times through the Internet and Web 2.0. The latter has potential to be more inclusive by obviating the need to take time from a busy schedule to travel and participate in physical meetings (Jankowski and Stasik 1997; Peng 2001; Rinner et al. 2008; Sakamoto and Fukui 2004).

The emerging concept of Geodesign provides a framework for organizing methods and technologies for constructing livability indicators, as well as integrating livability measurement into the transportation planning process. Geodesign is a technology-enhanced planning method that tightly couples proposal and plan generation with impact simulations that are sensitive to geographic context (Flaxman 2010). Geodesign has its conceptual roots in the work of Carl Steinitz, a pioneer in the use of GIS for landscape analysis and urban planning, as well as in Ian McHarg's Design with Nature ideas about constraints-based suitability mapping and map overlay techniques in planning and design (Dangermond 2009).

Geodesign consists of several core functionalities embedded in a digital environment with workspaces, design tools, and supportive workflows that are tightly coupled and synched (Abukhater and Walker 2010; Dangermond 2009). 
1. Sketching or the ability to generate and share scenarios in a collaborative environment. Sketches are quickly-derived, low-resolution plans or scenarios based on approximations and assumptions in map form.

2. Spatial models that can estimate the impacts and changes generated by the sketches, such as impacts on livability indicators

3. Feedback from modeling the effects of a sketch, supporting brainstorming, engagement and collaboration among participants.

4. Iteration or the ability to generate, test and adjust solutions repeatedly. This facilitates creative exploration of many alternatives, helps participants work together, and increases understanding of complex phenomena and measurement processes.

The Geodesign strategy can facilitate the application of livability concepts in transportation planning by removing artificial barriers between the construction and application of livability indicators. A Geodesign environment can combine the power of SDSS and MCA techniques for indicator construction with the capabilities of GIS and spatial analysis techniques for simulating futures based on proposed scenarios and assessing the livability impacts of these scenarios using indicators. Geodesign does not add new methods to the battery of techniques for indicator construction and application but nevertheless can dramatically transform the ways in which these techniques are used in the planning process by facilitating rapid conceptualization, articulation, visualization, modeling and assessment (Vargas-Moreno 2010).

While integrating livability concepts into transportation planning is laudable, these benefits can be dampened if livability indicators are simply inserted into the conventional linear, technocratic and rigid planning process that tends to discourage wider engagement (Nielsen 1995). As noted previously, livability and sustainability require balancing a wide spectrum of diverse and sometimes conflicting perspectives. Determining appropriate livability solutions - not just indicators - requires involvement from planners, experts, elected officials, citizens and other stakeholders in the indicator construction process as well as the application of indicators to determine strategies for creating livable communities. The construction process as described in this paper leads to 
internally consistent, transparent and external valid livability indicators; it does not describe how these indicators should be integrated into broader planning and decision processes. Geodesign can be a key component of a smarter livability planning process that is based not only on the proper measurement of this concept but also the collaborative search for livability solutions that are sensitive to local context (Abukhater and Walker 2010).

\section{Conclusion}

New emphases on livability and sustainability are creating demands for measuring and applying these concepts in transportation planning. These are complex, multidimensional concepts that require careful measurement if they to be applied appropriately in plan evaluation and benchmarking. This paper provided a framework for constructing and applying quantitative livability indicators. We critically reviewed principles of constructing indicators to describe multidimensional concepts such as livability, including multicriteria analysis (MCA) methods for deriving appropriate attributes and their relative importance. We focused on the construction of synoptic composite indicators (CI), although many of the principles can also be applied to individual indicators and indicator sets. We also discussed methods for customizing indicators to capture local context; this includes multi-actor multi-criteria (MAMCA) methods for explicitly maintaining diverse stakeholder perspectives into indicator construction and spatial analytic tools for modeling key geographic entities and relationships involved in transportation. We also discussed spatial decision support systems and the Geodesign concept for organizing tools and technologies for supporting the construction and application of indicators in transportation planning.

A direction for further research is empirical experience with MAMCA methods and the Geodesign process in the indicator construction and application processes, as well as tight integration of MAMCA methods into the Geodesign process. The Geodesign process has generated a great deal of attention, including a major conference (www.geodesignsummit.com) but empirical applications and evaluations are few so far. Despite this lack of experience, these methods are promising: MAMCA and Geodesign harmonize with calls a more inclusive planning process to address equity and social 
sustainability issues, as well as gain legitimacy for the process (Boschmann and Kwan 2008; Deka 2004; Martens 2006; NRC 2002). The methods also have potential to address disconnections between planning at different scales (such as neighborhood, metropolitan and regional scales) by coupling sketch plans and models at different scales and facilitating scenario modeling with these linked representations and plans (Abukhater and Walker 2010).

Another, longer-term research topic concerns developing dynamic indicator construction and analysis methods. The ability to capture, store and process data about transportation systems on an ongoing basis are also increasing, including real-time data feeds and volunteer geographic information from "citizen-sensors" (Goodchild 2007). Tracking changes in an indicator over time can provide new insights, benchmark existing policies and suggest new policy remedies (Norman 2010). Connecting livability or sustainability indicators with dynamic data updating and real-time data feeds is a natural progression. It is possible that we can learn something new about complex concepts such as livability and sustainability when we see these indicators vary with respect to their natural dynamics rather than at artificial snapshots in time. The dynamic behavior of indicators may also suggest new policy and planning interventions, as well as provide new ways to benchmark the effectiveness of implemented policies and plans. This will require new advances not only in the cyberinfrastructure for managing these data flows but also in capabilities for exploring and analyzing multiscale spatial and temporal patterns. Finer-grained updating of livability and sustainability data may also suggest more dynamic updating of the indicators, weights and aggregation methods to reflect changing reality as well as the accumulation of knowledge and insight that hopefully will occur from these new methods and decision strategies. 


\section{References}

Abukhater, A., and Walker, D. (2010) "Making smart growth smarter with GeoDesign," Directions Magazine, posted 19 July 2010; www.directionsmag.com

Allen, T.F.H. (2010) "Making livable sustainable systems unremarkable," Systems Research and Behavioral Science, 27, 469-479

Anselin, L. (1995) "Local indicators of spatial association - LISA". Geographical Analysis, 27, 93-115.

Banister, D. (2008) “The sustainable mobility paradigm,” Transport Policy, 15, 73-80.

Bartholomew, K. and Ewing, R. (2011) "Hedonic price effects of pedestrian- and transitoriented development," Journal of Planning Literature, 26, 18-34.

Bell, N., Schuurman, N. and Hayes, M.V. (2007) "Using GIS-based methods of multicriteria analysis to construct socio-economic deprivation indices," International Journal of Health Geographics, 6, pp.17.

Black, J.A., Paez, A. and Suthanaya, P.A. (2002) "Sustainable urban transportation: Performance indicators and some analytical approaches," Journal of Urban Planning and Development, 128, 184-209.

Black, W. R. (2010) Sustainable Transportation: Problems and Solutions, New York: Guilford.

Boschmann, E.E. and M.-P. Kwan. (2008) "Toward socially sustainable urban transportation: Progress and potentials." International Journal of Sustainable Transportation, 2, 138-157.

Brundtland G. H. (ed.) (1987) Our Common Future: The World Commission on Environment and Development. Oxford: Oxford University Press

Carruthers, J. and Clark, D. (2010) "Valuing environmental quality: a space-based strategy," Journal of Regional Science, 50, 801- 832.

Cherchye, L., Moesen, W., Rogge, N., Van Puyenbroeck, T., Saisana, M., Saltelli, A., Liska, R. and Tarantola, S. (2008) "Creating composite indicators with DEA and robustness analysis: the case of the Technology Achievement Index," Journal of the Operational Research Society, 59, 239-251. 
Conway, D., Li, C., Wolch, J., Kahle, C. and Jerrett, M. (2010) “A spatial autocorrelation approach for examining the effects of urban greenspace on residential property values," Journal of Real Estate Finance and Economics, 41, 150-169.

Cobb, C., Halstead, E. and Rowe, J. (1995) The Genuine Progress Indicator-Summary of Data and Methodology. Redefining Progress, Washington, DC.

Dangermond, J. (2009) "GIS: Designing Our Future." ArcNews, Summer 2009. esri.com/news/arcnews/summer09articles/gis-designing-our-future.html

de Chazal, J. (2010) "A systems approach to livability and sustainability: Defining terms and mapping relationships to link desires with ecological opportunities and constraints," Systems Research and Behavioral Science, 27, 585-597

de Chazal, J., Que, F., Lavorel, S. and Van Doorn, A. (2008) "Including multiple differing stakeholder values into vulnerability assessments of socio-ecological systems," Global Environmental Change, 18, 508- 520

Deakin, E. (2002) "Sustainable transportation: U.S. dilemmas and European experiences," Transportation Research Record 1792, 1-11.

Deka, D. (2004) "Social and environmental justice issues in urban transportation," in S. Hanson and G. Giuliano (eds.), The Geography of Urban Transportation. New York: Guilford Press, 332-355.

Diaz-Balteiro, L. and Romero, C. (2004) "In search of a natural systems sustainability index," Ecological Economics, 49, 401-405.

Dodgson, J., Spackman, M., Pearman, A.D. and Phillips, L.D. (2009) Multi-Criteria Analysis: A Manual. Department of the Environment, Transport and the Regions, London.

Dovers, S. (2001) "Informing institutions and policies," in J. Venning and J. Higgins (eds.), Towards Sustainability: Emerging Systems for Informing Sustainable Development, Sydney, Australia: University of New South Wales Press, 196-220

Duke, J.M. and Aull-Hyde, R. (2002) "Identifying public preferences for land preservation using the analytic hierarchy process," Ecological Economics, 42, 131-145.

Ebert, U. and Welsch, H. (2004) "Meaningful environmental indices: A social choice approach," Journal of Environmental Economics and Management, 47, 270-283. 
Ekins, P., Simon, S., Deutsch, L., Folke, C. and De Groot, R. (2003) “A framework for the practical application of the concepts of critical natural capital and strong sustainability, Ecological Economics, 44, 165-185.

EU (European Union) (2010) Making our Cities Attractive and Sustainable: How the EU Contributes to Improving the Urban Environment, Luxembourg: Publications Office of the European Union.

Ewing, R. (1993) "Transportation service standards - As if people matter," Transportation Research Record, 1400, 10-17.

Ewing, R. (1996) “"Beyond Speed: The next generation of transportation performance measures," in D. Porter (ed.), Performance Standards for Growth Management, Chicago: American Planning Association, 31-40.

Failing, L. and Gregory, R. (2003) "Ten common mistakes in designing biodiversity indicators for forest policy," Journal of Environmental Management, 68, 121-132

Figueria, J., Greco, S. and Ehrgott, M. (2005) Multiple Criteria Decision Analysis: State of the Art Surveys, Berlin: Springer.

Flaxman, M. (2010) “Geodesign: Fundamental principles," keynote address at GeoDesign Summit, Redlands, California: January 6-8, 201; available at. geodesignsummit.com/videos/day-one.html

Florida, R. (2002) The Rise of the Creative Class: And How It's Transforming Work, Leisure, Community and Everyday Life, New York: Basic Books.

Flowerdew, R. and Green, M. (1992) "Developments in areal interpolation methods and GIS," Annals of Regional Science, 26, 67-78.

Fotheringham, A.S. (2009) “'The problem of spatial autocorrelation' and local spatial statistics," Geographical Analysis, 41, 398-403.

Fotheringham A.S., Brunsdon C. and Charlton, M. (2000) Quantitative Geography: Perspectives on Spatial Data Analysis. Sage Publications, London.

Fotheringham A.S., Brunsdon C. and Charlton, M. (2002) Geographically Weighted Regression, Wiley, Chichester.

Garner, T. I. (1993) "Consumer expenditures and inequality: An analysis based on decomposition of the Gini Coefficient," Review of Economics and Statistics, 75, 134-138 
Geurs, K.T. and van Wee, B. (2004) "Land-use/transport interaction models as tools for sustainability impact assessment of transport investments: Review and research perspectives," European Journal of Transport and Infrastructure Research, 4, 333-335.

Goodchild, M. F. (2007) "Citizens as sensors: the world of volunteered geography," Geojournal, 69, 211-221.

Gotway, C.A. and Young, L.J. (2002) “Combining incompatible spatial data," Journal of the American Statistical Association, 97, 632-648.

Greene, R., Devillers, R., Luther, J.E. and Eddy, B.G. (2011) "GIS-based multiplecriteria decision analysis," Geography Compass, 5/6, 412-432.

Gutés, M. C. (1996) “The concept of weak sustainability," Ecological Economics, 17, 147-156.

Hanley, N., Schläpfer, F. and Spurgeon, J. (2003) "Aggregating the benefits of environmental improvements: Distance-decay functions for use and non-use values," Journal of Environmental Management, 68, 297-304.

Hediger, W. (1999) "Reconciling “weak" and "strong” sustainability," International Journal of Social Economics, 26, 1120 - 1144.

Hezri, A. and Dovers, S. R. (2006) "Sustainability indicators, policy and governance: Issues for ecological economics," Ecological Economics, 60, 86-99.

Horne, P., Boxall, P.C. and Adamowicz, W.L. (2005) "Multiple-use management of forest recreation sites: A spatially explicit choice experiment," Forest Ecology and Management, 207, 189-199.

Horner, M.W. (2002) "Extensions to the concept of excess commuting," Environment and Planning A, 34, 543-566.

Horner, M.W. (2004) "Spatial dimensions of urban commuting: A review of major issues and their implications for future geographical research," Professional Geographer, 56, 160-173.

Horner, M.W. and O'Kelly, M.E. (2007) “Is non-work travel excessive?” Journal of Transport Geography, 15, 411-416, 
Jankowski, P. (1995) "Integrating geographical information systems and multiple criteria decision-making methods," International Journal of Geographical Information Systems, 9, 251-273.

Jankowski, P., Nyerges, T.L., Smith, A., Moore, T.J. and Horvath, E. (1997) "Spatial group choice: A SDSS tool for collaborative spatial decision making," International Journal of Geographical Information Science, 11, 577-602.

Jankowski, P. and Stasik, M. (1997) "Design considerations for space and time distributed collaborative spatial decision making. Journal of Geographic Information and Decision Analysis, 1, 1-8.

Jiang, H. and Eastman, J.R. (2000) "Application of fuzzy measures in multi-criteria evaluation in GIS, International Journal of Geographical Information Science, 14, 173-184.

Keeney, R.L. (1980) Siting Energy Facilities, New York: Academic Press.

Kim, S., Cho, S.-H., Lambert, D. and Roberts, R. (2010) "Measuring the value of air quality: Application of the spatial hedonic model," Air Quality, Atmosphere \& Health, 3, 41- 51

Lakshmanan, T.R., Nijkamp. P., Rietveld, P. and Verhoef, E.T. (2001) "Benefits and costs of transport: Classification, methodologies and policies," Papers in Regional Science, 80, 139-164.

LeSage, J.P. and Pace, R.K. (2009) Introduction to Spatial Econometrics, Boca Raton: CRC Press.

Litman, T. (2007) "Developing indicators for comprehensive and sustainable transport planning," Transportation Research Record, 2017, 10-15.

Litman, T. (2010) "Sustainability and livability: Summary of definitions, goals, objectives and performance indicators," Victoria Transport Policy Institute, 19 July, http://www.vtpi.org/sus_liv.pdf

Macharis, C. (2007) "Multi-criteria analysis as a tool to include stakeholders in project evaluation, “ in Haezendonck, E. (ed.), Transport Project Evaluation: Extending the Social Cost-Benefit Approach, Cheltenham, Elgar, 115-131. 
Macharis, C., De Witte, A. and Ampe, J. (2009) "The multi-actor, multi-criteria analysis methodology for evaluation of transport projects: Theory and practice," Journal of Advanced Transportation, 43, 183-202.

Macharis, C., De Witte, A. and Turcksin, L. (2010) “The Multi-Actor Multi-Criteria Analysis (MAMCA) application in the Flemish long-term decision making process on mobility and logistics," Transport Policy, 17, 303-311.

Malczewski, J. (2000) "On the use of weighted linear combination method in GIS: Common and best practice approaches," Transactions in GIS, 4, 5-22.

Malczewski, J. (2004) "GIS-based land-use suitability analysis: A critical overview," Progress in Planning, 62, 3-65.

Malczewski, J. (2006) "Ordered weighted averaging with fuzzy quantifiers: GIS-based multicriteria evaluation for land-use suitability analysis," International Journal of Applied Earth Observation and Geoinformation, 8, 270-277

Malczewski, J., Chapman, T., Flegel, C., Walters, D., Shrubsole, D. and Healy, M.A. (2003) "GIS-multicriteria evaluation with ordered weighted averaging (OWA): case study of developing watershed management strategies," Environment and Planning A, 35, 1769-1784.

Martens, K. (2006) "Basing transport planning on principles of social justice." Berkeley Planning Journal, 40, 1-17

Massam, B.H. (1999) "The classification of quality of life using multi-criteria analysis," Journal of Geographic Information and Decision Analysis, 3 (2), 1-8.

Miller, H.J. and Wentz, E.A. (2003) "Representation and spatial analysis in geographic information systems," Annals of the Association of American Geographers, 93, 574-594.

Munda, G. (2005) “'Measuring sustainability': A multi-criterion framework," Environment, Development and Sustainability, 7, 117-134.

Munda, G. and Nardo, M. (2005) "Constructing consistent composite indicators: The issue of weights," research report, European Commission Directorate-General Joint Research Centre Institute for the Protection and Security of the Citizen, Luxembourg. 
Myers, D. (1987) “Community-relevant measurement of quality of life: A focus on local trends," Urban Affairs Review, 23, 108-125.

NRC (National Research Council) (2002) Community and Quality of Life: Data Needs for Informed Decision Making, Washington, DC: National Academy Press.

Neumeyer, E. (2003) Weak versus Strong Sustainability: Exploring the Limits of Two Opposing Paradigms, $2^{\text {nd }}$ edition, Edward Elgar, Cheltenham, UK.

Niedzielski, M.A. (2006) "A spatially disaggregated approach to commuting efficiency," Urban Studies, 43, 2485-2502.

Nielsen, O.A. (1995) "Using GIS in Denmark for traffic planning and decision support," Journal of Advanced Transportation, 29, 335-354.

Nijkamp, P., Rietveld, P. and Voogd, H. (1990) Multicriteria Evaluation in Physical Planning, Amsterdam: Elsevier.

Norman, P. (2010) "Identifying change over time in small area socio-economic deprivation," Applied Spatial Analysis and Policy, 3, 107-138

Nyerges, T. and Jankowski, P. (2010) Regional and Urban GIS: A Decision Support Approach, New York: Guilford.

O'Kelly, M.E. (2010) "Entropy-based spatial interaction models for trip distribution," Geographical Analysis, 42, 422-487.

Openshaw, S. (1978) "An optimal zoning approach to the study of spatially-aggregated data," in I. Masser and P.J.B. Brown (eds.) Spatial Representation and Spatial Interaction, Leiden: Martinus Nijhof, 93-113.

Openshaw, S. and Rao, L. (1995) "Algorithms for reengineering 1991 census geography," Environment and Planning A, 27, 425-446.

Openshaw, S. and Taylor, P.J. (1979) "A million or so correlation coefficients: Three experiments on the modifiable areal unit problem," in N. Wrigley (ed.) Statistical Applications in the Spatial Sciences, London: Pion, 127-144.

Papageorgiou, G.J. (1978) "Spatial externalities I: Theory," Annals of the Association of American Geographers, 68, 465-476.

Peng, Z.-R. (2001) "Internet GIS for public participation," Environment and Planning B: Planning and Design, 28, 889- 905. 
Prugh, T., Costanza, R. and Daly, H., (2000) The Local Politics of Global Sustainability. Island Press, Washington, DC.

Ramanathan, R. (2006) "ABC inventory classification with multiple-criteria using weighted linear optimization," Computers and Operations Research, 33, 695-700.

Rinner, C., Keßler, C. and Andrulis, S. (2008) "The use of Web 2.0 concepts to support deliberation in spatial decision-making," Computers, Environment and Urban Systems, 32, 386-395.

Rinner, C. and Malczewski, J. (2002) "Web-enabled spatial decision analysis using Ordered Weighted Averaging (OWA), Journal of Geographical Systems, 4, 385403.

Saaty, T.L. (1980) The Analytic Hierarchy Process. London: McGraw-Hill Inc.

Saaty, T.L. (1990) "How to make a decision: The analytic hierarchy process," European Journal of Operational Research, 48, 9-26.

Sagar, A.D. and Najam, A. (1998) "The human development index: a critical review," Ecological Economics, 25, 249-264.

Saisana, M., Saltelli A. and Tarantola, S. (2005) "Uncertainty and sensitivity analysis techniques as tools for the quality assessment of composite indicators," Journal of the Royal Statistical Society A, 168, Part 2, 307-323.

Saisana, M. and Tarantola, S. (2002) State-of-the-art Report on Current Methodologies and Practices for Composite Indicator Development. Report EUR 20408 EN. European Commission-Joint Research Centre, Ispra.

Sakamoto, A. and Fukui, H. (2004) "Development and application of a livable environment evaluation support system using Web GIS," Journal of Geographical Systems, 6, 175-195.

Schenkerman, S. (1994) "Avoiding rank reversal in AHP decision-support models," European Journal of Operational Research, 74, 407-419.

Schuurman N., Bell N., Dunn J.R. and Oliver L. (2007) "Deprivation indices, population health and geography: An evaluation of the spatial effectiveness of indices at multiple scales," Journal of Urban Health, 84, 591-603 
Shafer, C.S., Lee, B.K. and Turner, S. (2000) "A tale of three greenway trails: User perceptions related to quality of life," Landscape and Urban Planning, 49, 163178.

Strager, M.P. and Rosenberger, R.S. (2006) "Incorporating stakeholder preferences for land conservation: Weights and measures in spatial MCA," Ecological Economics, 57, 627-639.

Triantaphyllou, E. and Sanchez, A. (1997) "A sensitivity analysis approach for some deterministic multicriteria decision making methods," Decision Science 28, 151194.

Turban, E. (1993) Decision Support and Expert Systems (3th Ed.) Management Support Systems. New York: Macmillan Publishing Company.

UNCSD (United Nations Commission on Sustainable Development) (2001) Indicators of Sustainable Development: Guidelines and Methodologies. United Nations Commission on Sustainable Development, United Nations, New York, New York.

UNDP (United Nations Development Program) (1990) Human Development Report 1990. Oxford University Press, New York and Oxford.

USDOT (United States Department of Transportation) (2009) "Partnership sets forth six 'livability principles' to coordinate policy," press release, U.S. Department of Transportation, Office of Public Affairs, DOT 80-0916 June 2009; http://www.dot.gov/affairs/2009/dot8009.htm.

USDOT (United States Department of Transportation) (2010) Livability in Transportation Guidebook: Planning Approaches that Promote Livability, U.S. Department of Transportation, Federal Highway Administration, Federal Transit Administration, FHWA-HEP-10-028.

Van Acker, V., Witlox, F. and van Wee, B. (2007) "The effects of the land use system on travel behaviour: a structural equation modeling approach". Transportation Planning and Technology, 30 (4), 331-353.

Vargas-Moreno, J.C. (2010) “GeoDesign: The emergence of a tight-coupling approach in GIS and spatial planning," Planning Technology Today; planningtechtoday.org; posted Apr 26, 2010 
Wackernagel, M. and Rees, W.E. (1996) Our Ecological Footprint: Reducing Human Impact on the Earth. New Society Publishers, Gabriola Island.

Wang, Y.-M. and Elhag, T.M.S. (2006) "An approach to avoiding rank reversal in AHP," Decision Support Systems, 42, 1474-1480.

WBCSD (World Business Council for Sustainable Development) (2004) Mobility 2030: Meeting the Challenges to Sustainability, World Business Council for Sustainable Development. http://www.wbcsd.org/web/publications/mobility/mobility-full.pdf

Witlox, F. (2005) "Expert systems in land-use planning: An overview". Expert Systems with Applications, 29 (2), 437-445.

Witlox, F., Antrop, M., Bogaert, P., De Maeyer, P., Derudder, B., Neutens, T., Van Acker, V. and Van de Weghe, N. (2009) "Introducing functional classification theory to land use planning by means of decision tables," Decision Support Systems, 46 (4), 875-881.

Witlox, F., Debauche, W., Macharis, C., Van Hoeck, E. and Verlinde S. (2010) Nighttime Delivery: A Potential Option in Urban Distribution. Brussels: Belgian Science Policy report 2010.

Wong, D. (2009) "The modifiable areal unit problem," in A.S. Fotheringham and P.A. Rogerson (eds.) The SAGE Handbook of Spatial Analysis, Los Angeles: SAGE, 105-123.

$\mathrm{Xu}, \mathrm{Z}$. (2005) "An overview of methods for determining OWA weights," International Journal of Intelligent Systems, 20, 843-865.

Yager, R.R. (1988) "On ordered weighted averaging aggregation operators in multicriteria decision making," IEEE Transactions on Systems, Man and Cybernetics, $18,183-190$.

Yager R.R. (1997) "On the inclusion of importances in OWA aggregations"', in R.R. Yager and J. Kacprzyk (eds.) The Ordered Weighted Averaging Operators: Theory and Applications, Boston: Kluwer Academic, 41-59.

Yitzhaki, S. (1979) "Relative deprivation and the Gini coefficient," Quarterly Journal of Economics, 93, 321-324

Zeleny, M. (1982) Multiple Criteria Decision Making, New York: McGraw-Hill. 
Zhou, P. and Ang, B.W. (2008) "Indicators for assessing sustainability performance," in K. B. Misra (ed.) Handbook of Performability Engineering, London: Springer Verlag, 905-918.

Zhou, P. and Fan, L. (2007) "A note on multiple criteria ABC inventory classification using weighted linear optimization," European Journal of Operational Research, 182, 1488-1491.

Zhou, P., Ang, B.W. and Poh, K.L. (2006) "Comparing aggregating methods for constructing the composite environmental index: An objective measure," Ecological Economics, 59, 305-311.

Zietsman, J. and Rilett L.R. (2008) "Using sustainable transportation performance measures in corridor decision making". In Towards a Definition of Measurable Environmentally Sustainable Transport, Proceedings of Seminar: COST 356 Oslo, Norway, February 20, 2008. Oslo: Institute of Transport Economics, 105124 